\title{
Thoracic epidural analgesia reduces gastric microcirculation in the pig
}

\author{
Rikard Ambrus ${ }^{1 *} \mathbb{D}$, Rune B. Strandby ${ }^{1}$, Niels H. Secher ${ }^{2}$, Kim Rünitz ${ }^{2}$, Morten B. S. Svendsen ${ }^{3}$, Lonnie G. Petersen ${ }^{2}$, \\ Michael P. Achiam ${ }^{1}$ and Lars B. Svendsen ${ }^{1}$
}

\begin{abstract}
Background: Thoracic epidural analgesia (TEA) is used for pain relief during and after abdominal surgery, but the effect of TEA on the splanchnic microcirculation remains debated. We evaluated whether TEA affects splanchnic microcirculation in the pig.

Methods: Splanchnic microcirculation was assessed in nine pigs prior to and 15 and 30 min after induction of TEA. Regional blood flow was assessed by neutron activated microspheres and changes in microcirculation by laser speckle contrast imaging (LSCl).

Results: As assessed by LSCI 15 min following TEA, gastric arteriolar flow decreased by $22 \%$ at the antrum ( $p=0$. 020) and by $19 \%$ at the corpus ( $p=0.029$ ) of the stomach. In parallel, the microcirculation decreased by $19 \%$ at the antrum ( $p=0.015)$ and by $20 \%$ at the corpus $(p=0.028)$. Reduced arteriolar flow and microcirculation at the antrum was confirmed by a reduction in microsphere assessed regional blood flow 30 min following induction of TEA $(p=0.048)$. These manifestations took place along with a drop in systolic blood pressure $(p=0.030)$, but with no significant change in mean arterial pressure, cardiac output, or heart rate.
\end{abstract}

Conclusion: The results indicate that TEA may have an adverse effect on gastric arteriolar blood flow and microcirculation. $\mathrm{LSCl}$ is a non-touch technique and displays changes in blood flow in real-time and may be important for further evaluation of the concern regarding the effect of thoracic epidural anesthesia on gastric microcirculation in humans.

Trial registrations: Not applicable, non-human study.

Keywords: Splanchnic microcirculation, Thoracic epidural analgesia, Laser speckle contrast imaging, Pigs

\section{Background}

Thoracic epidural analgesia (TEA) is used for abdominal surgery to reduce intra- and postoperative pain, improve postoperative respiratory function, and to attenuate the surgical stress response [1]. Also, epidural analgesia has been shown to be associated with reduced risk of postoperative mortality and has beneficial effects on postoperative cardiovascular complications [2]. However, the effect of TEA on the splanchnic microcirculation remains unclear [3] and a concern is whether TEA affects splanchnic blood flow, since poor surgical outcome is correlated to ischemia at the anastomosis [4].

\footnotetext{
* Correspondence: riam@dadlnet.dk

${ }^{1}$ Department of Surgical Gastroenterology C, Rigshospitalet, University of Copenhagen, Blegdamsvej 9, DK - 2100 Copenhagen $\varnothing$, Denmark Full list of author information is available at the end of the article
}

TEA-mediated reduced blood pressure could be of importance for the splanchnic microcirculation, since probes at the mesenteric arteries have demonstrated a TEA-mediated reduced blood flow [5, 6]. However, a reduced splanchnic blood flow in response to TEA has not been confirmed in experimental studies with focus on splanchnic microcirculation and oxygenation $[7,8]$. Furthermore, laser Doppler flowmetry indicates increased postoperative gastric mucosal microcirculation with the use of TEA [9]. Thus, the effects of TEA on splanchnic microcirculation are inconsistent and conflicting results likely reflect different approaches to evaluate the microcirculatory flow and oxygenation. For example, both evaluation of tissue oxygenation and laser Doppler flowmetry require contact to the surface of the tissue $[7,9]$ and that could affect the measurements. 


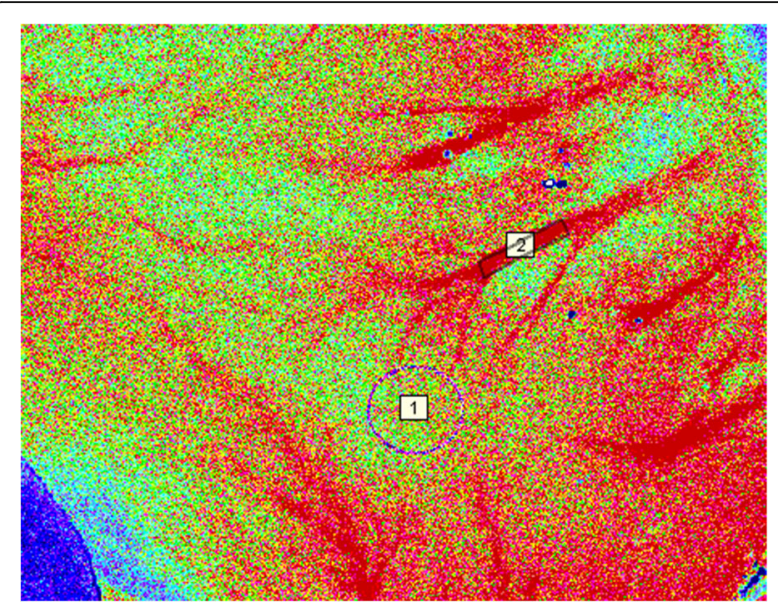

Fig. 1 A representative illustration of the regions of interest as measured by laser speckle contrast imaging (at corpus of the stomach). 1: Corpus microcirculation; 2: An arteriole

The aim of the present study was to evaluate the effect of TEA on splanchnic microcirculation in pigs with the use of microspheres $[10,11]$ and laser speckle contrast imaging (LSCI) for non-contact assessment [12]. We hypothesized that TEA would maintain splanchnic microcirculation.

\section{Methods}

The study was conducted under supervision of the veterinarians at the Department of Experimental Medicine, The Panum Institute, University of Copenhagen and was approved by the Danish Animal Experiments Inspectorate (2012-15-2934-00186). According to the replacement, reduction, and refinement principle [13], the current trial was performed after evaluation of the interobserver reproducibility of LSCI determined microcirculation [12], and followed by another study comparing the microcirculation assessed by the LSCI, microspheres, and indocyanine green technique (Nerup et al., unpublished).

\section{Anesthesia and monitoring}

Nine healthy female pigs (Danish Landrace/Yorkshire; weight $32.0 \pm 1.8 \mathrm{~kg}$ (mean $\pm \mathrm{SD}$, aged 9-10 weeks) were sedated with a standardized mix of intramuscular Zoletil vet. (5 mg/kg), xylazine, ketamine, methadone, and butorphanol. Following placement of venous access in both ears, anesthesia was maintained with propofol (15 $\mathrm{mg} / \mathrm{kg} / \mathrm{h})$ and fentanyl $(5 \mu \mathrm{g} / \mathrm{kg} / \mathrm{h})$. After endotracheal intubation, positive pressure ventilation was established with 25 - 40 \% oxygen. Catheters (8 F, Unomedical, Denmark) were then established in the left and right femoral arteries for blood sampling and arterial pressure monitoring. Ventilation was adjusted to an arterial carbon dioxide $\left(\mathrm{PaCO}_{2}\right)$ of $4.5-6.5$ and an oxygen tension $\left(\mathrm{PaO}_{2}\right)$ of $11-15 \mathrm{kPa}$, as controlled every $30^{\text {th }}$ min $\left(\mathrm{ABL}^{\mathrm{T}}\right.$ 700; Radiometer Medical ApS, Copenhagen, Denmark). A gastric tube was inserted to empty gastric content and lactated Ringer's solution was administrated intravenously at $5 \mathrm{ml} / \mathrm{kg} / \mathrm{h}$.

An epidural catheter (Epidural Minipack System 1, Smiths Medical, Hranice, Czech Republic) was placed at 7 th -8 th or 8 th -9 th thoracic intervertebral space using the "loss of resistance" technique. Thereafter, a pulmonary artery catheter (7 F, Edwards, Life Sciences, Irvine, CA, USA) was inserted via the right external jugular vein for determination of central pressures and

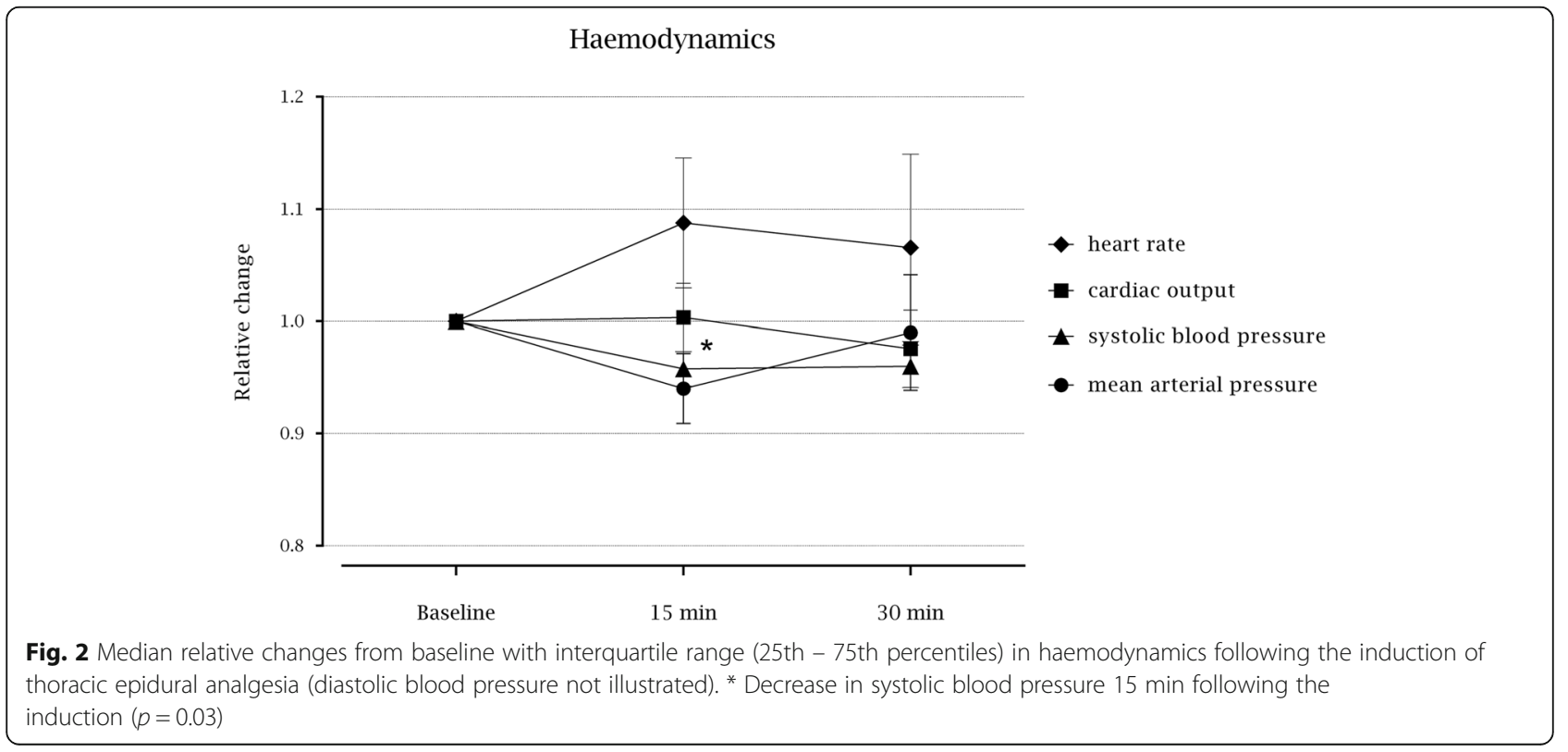


Table 1 Absolute hemodynamic values at baseline, $15 \mathrm{~min}$, and 30 min after the induction of thoracic epidural analgesia, presented as median with interquartile range (25th - 75th percentiles)

\begin{tabular}{llll}
\hline Variable & Baseline & $15 \mathrm{~min}$ & $30 \mathrm{~min}$ \\
\hline $\begin{array}{l}\text { Systolic arterial pressure } \\
\text { (mmHg) }\end{array}$ & $115(108-$ & $104(101-$ & $105(103-$ \\
$\begin{array}{l}\text { Diastolic arterial pressure } \\
\text { (mmHg) }\end{array}$ & $66(60-69)$ & $59(50-64)$ & $60(51-66)$ \\
$\begin{array}{l}\text { Mean arterial pressure } \\
(\mathrm{mmHg})\end{array}$ & $85(70-90)$ & $74(72-81)$ & $76(72-84)$ \\
Heart rate (beats min & & & $109)$ \\
Cardiac output $\left(\mathrm{ml} \mathrm{min}^{-1}\right)$ & $64(57-76)$ & $68(58-89)$ & $69(53-84)$ \\
& $3100)$ & $3350)$ & $3150)$ \\
\hline
\end{tabular}

cardiac output by thermodilution (Vigilance ${ }^{\bullet}$ Monitor, Edwards Critical Care Division, Irvine). Also, a catheter (8 F, Unomedical, Denmark) was placed in the left ventricle of the heart via the left carotid artery. The catheters were flushed with heparinized lactated Ringer's solution $(100 \mathrm{IE} / \mathrm{ml}$ ) after use. A $10 \mathrm{~F}$ catheter (Unomedical, Denmark) was surgically placed in the bladder for monitoring urine output. Hemodynamic data were recorded using Powerlab 16/35 (AD Instruments, Dunedin, New Zealand). All the vascular catheters were placed by dissection, assisted by the veterinarian. The gauzes used during the dissection were weighted and hemoglobin and hematocrit values were taken prior to and after the instrumentation to assess any bleeding.

\section{Surgical procedure}

After instrumentation, the intestines, stomach, and liver were exposed by a midline laparotomy. No pressure or strangulation of the organs was introduced or observed. The liver (segment 3), the small intestine $(10 \mathrm{~cm}$ from the caecum), and the antrum $(3 \mathrm{~cm}$ from the pylorus) and the corpus $(3 \mathrm{~cm}$ from the greater curvature) of the stomach were marked to ensure regions of interest (ROI).

\section{Experimental protocol}

After 15 min of stabilization following the laparotomy, TEA was induced by $2 \mathrm{ml}$ lidocaine/adrenaline (2\%, SAD, Amgros I/S, Denmark), followed by bolus injection of $2 \mathrm{ml}$ bupivacaine $(5 \mathrm{mg} / \mathrm{ml}, \mathrm{SAD})$ and infusion of $2 \mathrm{ml} / \mathrm{h}$ bupivacaine/morphine $(2.5 \mathrm{mg} / 50 \mu \mathrm{g} / \mathrm{ml})$, i.e., half of the dose used for adult patients taking the weight of the animals into account.

The effect of TEA on the splanchnic microcirculation was assessed three times: at baseline, $15 \mathrm{~min}$, and 30 min following induction of TEA. LSCI was used to determine changes in microcirculation at each ROI. Simultaneously, a suspension of microspheres was injected into the left ventricle of the heart, and blood from the femoral arterial was obtained by automated aspiration (6 ml/min) (Harvard Apparatus PHD 2000 Infusion/ Withdraw Pump, MA, USA) starting $30 \mathrm{~s}$ prior to the injection and continued for $120 \mathrm{~s}$. This rate was used as reference sample flow when regional blood flow was calculated.

At the end of each trial, the pig was euthanized by intravenous pentobarbital and tissue samples (approximately $1 \mathrm{~g}$ ) were collected from each ROI. The samples were weighed (Quintix ${ }^{\circ}$, Sartorius, Bie \& Berntsen A/S, Denmark) and dried overnight at $70{ }^{\circ} \mathrm{C}$ together with the blood samples. After drying, the samples were quantified for microspheres (BioPAL Inc., Worcester, MA, USA) to calculate regional blood flow.

\section{Microcirculation}

Regional blood flow was estimated using $15 \mu \mathrm{m}$ neutron activated microspheres (BioPAL Inc., Worcester, MA, USA). The calculation [14] is based on the assumption that the microspheres are lodged in the capillaries [11] and that delivery of microspheres to a ROI depends on tissue blood flow. Tissue blood flow $u_{\text {tissue }}(\mathrm{ml} / \mathrm{min} / \mathrm{g})$ is then calculated as:

$$
\frac{u_{\text {tissue }}=u_{\text {ref }} \cdot n_{\text {tissue }}}{m_{\text {tissue }} \cdot n_{\text {ref }}}
$$

where $u_{r e f}$ is the reference sample flow, $n_{\text {tissue }}$ represents the sphere count in the sample, $\mathrm{m}_{\text {tissue }}$ is the mass of the sample, and $\mathrm{n}_{\text {ref }}$ is the sphere count in the reference sample.

The microcirculation was assessed with LSCI using a laser wavelength of $785 \mathrm{~nm}$ (MoorFLPI, Moor Instruments Ltd, Axminster, UK) placed parallel to the surface of the tissue and fixed $25 \mathrm{~cm}$ above each ROI. The ROIs were set to cover a $1 \mathrm{~cm}^{2}$ surface of the tissue to reduce variability of the measurements [15], with a sampling rate of 1 frame/s over $30 \mathrm{~s}$. In contrast to microspheres, LSCI cannot measure absolute flow and results are expressed as flux in arbitrary laser speckle perfusion units which however are linearly related to absolute flow [12]. To further illustrate changes in blood flow following the induction of TEA, the flux at an arteriole adjacent to each ROI was determined post hoc using the software delivered by the manufacturer (Fig. 1).

\section{Statistics}

Hemodynamic data represent the mean over $30 \mathrm{~s}$ recorded by the data acquisition software, whereas microcirculation at each ROI was extracted using a fixed algorithm in order to limit bias in selection of data [12]. Other statistic evaluations were calculated using IBM SPSS 20.0 (SPSS Inc., Chicago, IL, USA). Repeated measures were calculated using the nonparametric Friedman's 
test with Bonferroni correction for multiple comparisons and Wilcoxon signed-rank test was used when comparing two time points. $P$-values $<0.05$ was considered statically significant and data are presented both as relative changes from baseline and absolute values as median with interquartile range (25th -75 th percentiles) for relevant interpretation of the findings.

\section{Results}

There was a decrease in systolic blood pressure following induction of TEA $(p=0.030)$, but no statically significantly changes in diastolic $(p=0.161)$ or mean arterial pressure $(p=0.154)$, cardiac output $(p=0.326)$, or heart rate $(p=0.236)$ (Fig. 2 and Table 1$)$.

\section{LSCl-determined arteriolar blood flow}

Fifteen minutes after the induction of TEA, flow at the arterioles decreased by $22 \%$ at the antrum ( $p=$ $0.020)$ and by $19 \%$ at the corpus $(p=0.029)$ of the stomach and the values remained low after $30 \mathrm{~min}(p$ $=0.001$ and $p=0.012$, respectively) (Fig. $3 \mathrm{a}$ and Table 2). In contrast, there was no significant change in arteriolar blood flow at the small intestine following the induction of TEA $(p=0.767)$.

\section{A LSCI-determined arteriolar flow}

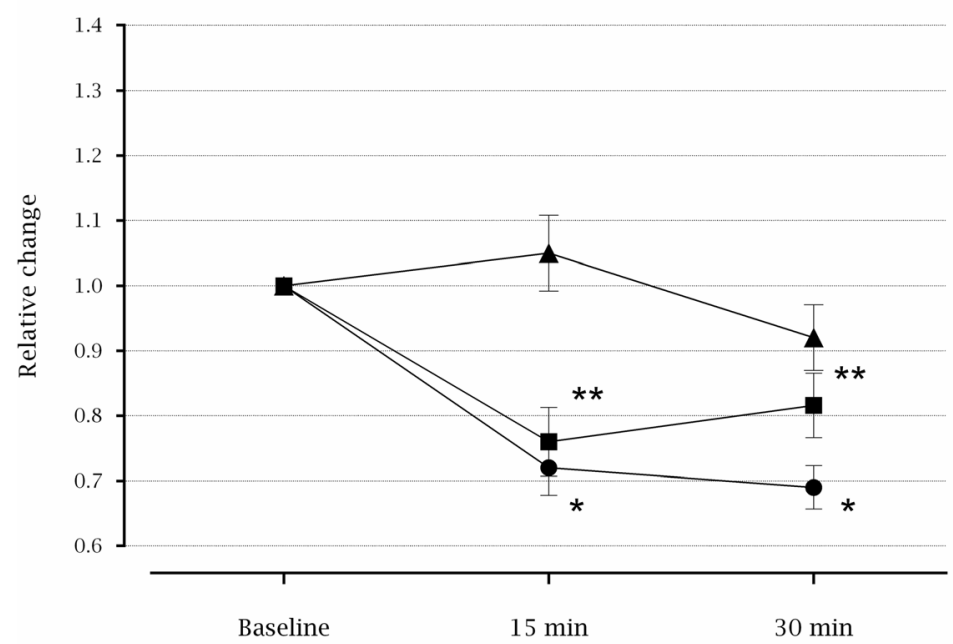

\section{B}

LSCI-determined microcirculation

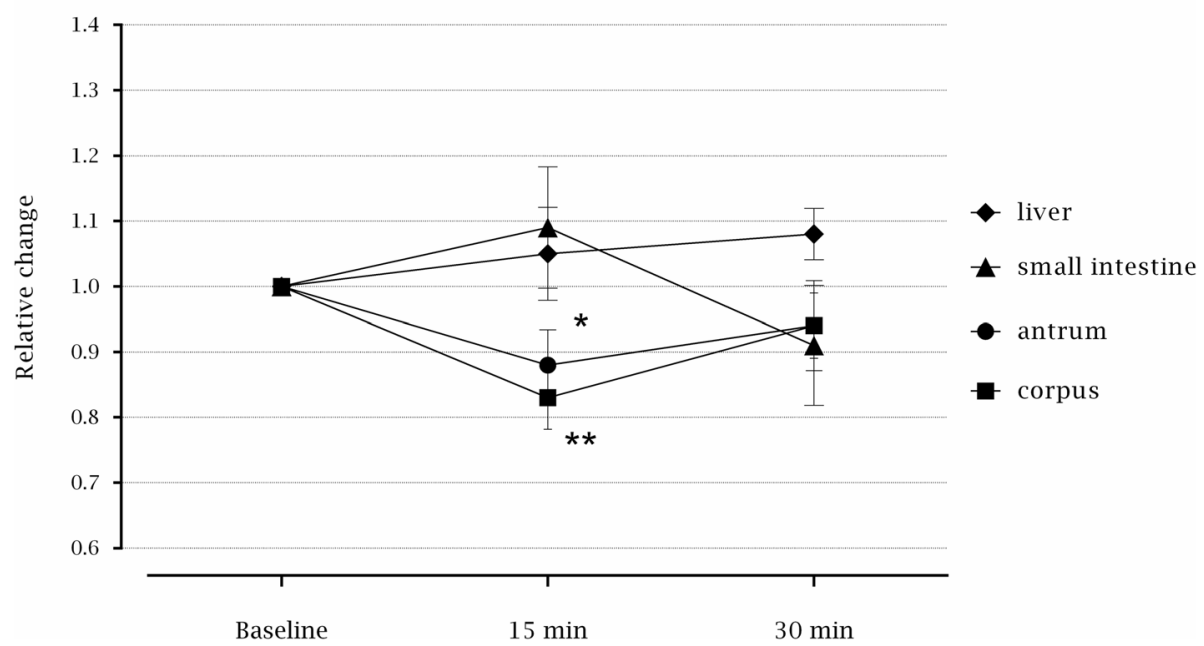

Fig. 3 Median relative changes from baseline with interquartile range (25th - 75th percentiles) in microcirculation determined using LSCI following thoracic epidural analgesia at arterioles (a) and regions of interest $(\mathbf{b}) .{ }^{*}$ and ${ }^{* *}$ Decreased microcirculation at antrum and corpus, respectively $(p<0.05)$ 
Table 2 LSCl-determined arteriolar blood flow in laser speckle perfusion units at baseline, $15 \mathrm{~min}$, and $30 \mathrm{~min}$ after the induction of thoracic epidural analgesia presented as median with interquartile range (25th - 75th percentiles)

\begin{tabular}{llll}
\hline $\begin{array}{l}\text { Anatomic } \\
\text { region }\end{array}$ & Baseline & 15 min & $30 \mathrm{~min}$ \\
\hline Stomach: & $1298.86(1056.37-$ & $1019.52(870.66-$ & $966.23(811.12-$ \\
Antrum & $1464.11)$ & $1168.86)$ & $1147.36)$ \\
\multicolumn{1}{c}{ Corpus } & $1164.43(1000.18-$ & $944.39(832.09-$ & $953.59(773.97-$ \\
& $1267.40)$ & $1194,16)$ & $1172.91)$ \\
Small & $1117.95(1034.13-$ & $1252.54(961.56-$ & $1220.18(1008.93-$ \\
intestines & $1243.63)$ & $1346.93)$ & $1336.27)$ \\
\hline
\end{tabular}

\section{LSCl-determined microcirculation at regions of interest}

In parallel with the changes in arteriolar blood flow there was a decrease in microcirculation by $19 \%$ at the antrum $(p=0.015)$ and by $20 \%$ at the corpus $(p=0.028)$ of the stomach following induction of TEA (Fig. 3b and Table 3) and these values were not significantly different from the decrease in arteriolar blood flow ( $p=0.233$ for antrum and $p=0.075$ for corpus). The decrease in LSCIdetermined microcirculation remained low, but was not statistically significant $30 \mathrm{~min}$ following induction of TEA ( $p=0.062$ for antrum and $p=0.091$ for corpus). Also, there were no changes in LSCI-determined microcirculation after TEA for the liver $(p=0.115)$ or for the small intestine $(p=0.895)$.

\section{Regional blood flow assessed by microspheres}

There was no decrease in regional blood flow to the antrum of the stomach 15 min after induction of TEA ( $p=$ $0.499)$ but after $30 \mathrm{~min}$ there was detected a decrease ( $p$ $=0.048$ ). In contrast, regional blood flow to corpus of the stomach, liver, and small intestine did not change significantly $(p=0.417, p=0.819$, and $p=0.657$, respectively) (Fig. 4 and Table 4 ).

Table 3 Absolute LSCl-determined microcirculation in laser speckle perfusion units at regions of interest, at baseline, $15 \mathrm{~min}$, and $30 \mathrm{~min}$ after the induction of thoracic epidural analgesia, presented as median with interquartile range (25th -75 th percentiles)

\begin{tabular}{llll}
\hline $\begin{array}{l}\text { Region of } \\
\text { interest }\end{array}$ & Baseline & $15 \mathrm{~min}$ & $30 \mathrm{~min}$ \\
\hline Stomach: & $953.60(700.90-$ & $777.30(605.83-$ & $796.60(608.95-$ \\
Antrum & $1122.50)$ & $843.60)$ & $913.65)$ \\
\multicolumn{1}{c}{ Corpus } & $815.30(679.20-$ & $649.05(622.25-$ & $696.70(622.80-$ \\
& $910.77)$ & $711.38)$ & $90467)$ \\
Liver & $442.30(388.00-$ & $414.65(389.80-$ & $458.00(450.40-$ \\
& $478.00)$ & $483.10)$ & $491.45)$ \\
Small & $937.40(791.15-$ & $1019.95(814.20-$ & $907.65(727.60-$ \\
intestines & $1033.75)$ & $1121.35)$ & $1080.68)$ \\
\hline
\end{tabular}

\section{Discussion}

Without contact to the tissue, this study evaluated the effect of thoracic epidural analgesia (TEA) on liver, gastric, and small intestinal microcirculation by use of laser speckle contrast imaging (LSCI) and determination of regional blood flow by microspheres. In contrary to our hypothesis of maintained splanchnic microcirculation following the activation of TEA, microcirculation and blood flow in the arterioles appeared to decrease at both the antrum and corpus of the stomach following the induction of TEA and was accompanied by a drop in systolic blood pressure. Also, regional blood flow determined by microspheres at the antrum decreased following the induction of TEA, while flow to the liver and the small intestine was maintained.

Reduced systolic blood pressure and parallel decreases in microcirculation at the antrum and corpus of the stomach following induction of TEA are in line with studies in humans, indicating a TEA-mediated reduced splanchnic circulation [5, 6, 16-18]. Blockade of sympathetic nerve fibres with TEA results in peripheral and splanchnic vasodilatation and reduction in vascular resistance $[19,20]$, which we consider would increase the microcirculatory flow. However, the results indicate a reduced gastric microcirculation, while liver and small intestine microcirculation were sustained following induction of TEA. We cannot provide a simple explanation for these findings, but a rationalization may be the distribution and function of the intestinal vasculature with first- and second-order arterioles located in the serosal and submucosal layers, respectively, supplying a system of smaller third-order arterioles and terminal arterioles [21]. Each terminal arteriole supplies one or several villi, the muscle layer that overlays the perfused region and crypt regions associated with each villus [22]. The villi are sensitive to changes in oxygen supply and oxygen dependency may manifest with as little as a $30 \%$ reduction in blood flow [23]. Therefore, it might be that blood is shunted away from the proximal to the distal part of the gastrointestinal tract (i.e., from the stomach to the small intestine) that has the largest number of villi. Such redistribution of flow could compensate for a reduced microcirculation to the villi by attenuated blood pressure and blood flow following induction of TEA. The stable microcirculation in the liver may be due to its complex blood supply with the largest part of flow derived from the portal circulation [24]. Splanchnic vasodilation following induction of TEA increases venous capacity, with subsequent increase in portal flow and therefore maintained liver microcirculation (the hepatic arterial buffer response) [25].

Reduced gastric microcirculation with TEA adds to the concern regarding the risk of anastomotic ischemia after, e.g., Ivor-Lewis esophagectomy where gastric 


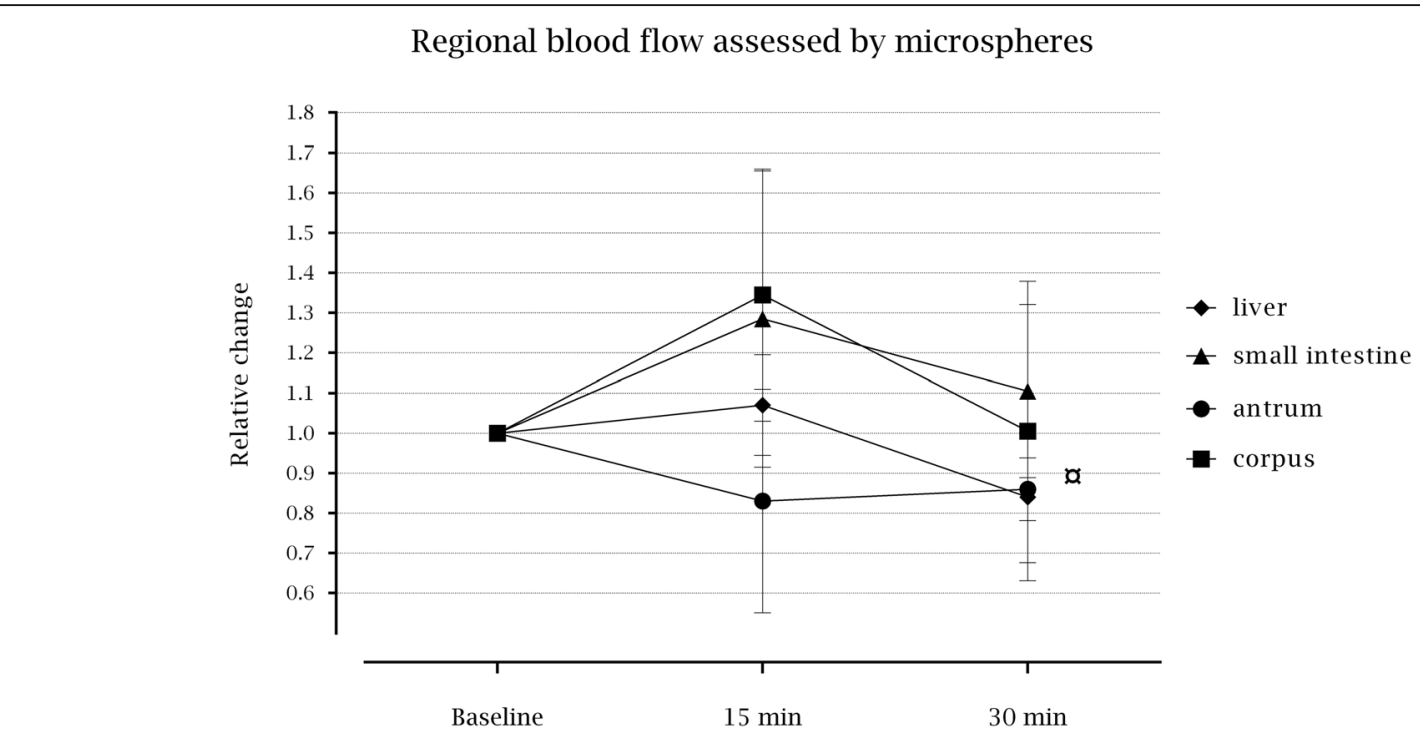

Fig. 4 Median relative changes from baseline with interquartile range (25th - 75th percentiles) in regional blood flow assessed by microspheres following the induction of thoracic epidural analgesia. a Decreased regional blood flow at antrum of the stomach 30 min following the induction $(p=0.048)$

continuity is re-established using the corpus of the stomach [26]. The integrity of an anastomosis depends on several factors, including surgical technique and viability of the muscle layers, but increased strain and local ischemia are believed to be main reasons for anastomotic leakage $[27,28]$. A decrease in corpus microcirculation may question routine intraoperative use of epidural analgesia during esophagectomy, since diminished microcirculation has deleterious effect on the healing of the gastric conduit $[4,29]$. An alternative may be that epidural anesthesia for postoperative analgesia after esophagectomy is activated only prior to the termination of general anesthesia.

The discrepancy between changes in regional blood flow as estimated by microspheres and microcirculation as assessed with LSCI likely reflects the different aspects of the microcirculation probed by the two techniques. The microspheres estimate a "snapshot" of absolute tissue blood flow rate $(\mathrm{ml} / \mathrm{min} / \mathrm{g})$, while LSCI displays mean values of flux recorded (here over $30 \mathrm{~s}$ ). Furthermore, the tissue samples obtained for calculations of

Table 4 Absolute regional blood flow $(\mathrm{ml} / \mathrm{min} / \mathrm{g})$ assessed by microspheres at baseline, $15 \mathrm{~min}$, and $30 \mathrm{~min}$ after the induction of thoracic epidural analgesia, presented as median with interquartile range (25th - 75th percentiles)

\begin{tabular}{llll}
\hline Anatomic region & Baseline & $15 \mathrm{~min}$ & $30 \mathrm{~min}$ \\
\hline Stomach: Antrum & $0.20(0.08-0.21)$ & $0.14(0.08-0.31)$ & $0.11(0.06-0.17)$ \\
$\quad$ Corpus & $0.14(0.05-0.23)$ & $0.15(0.08-0.24)$ & $0.13(0.09-0.28)$ \\
Liver & $0.23(0.10-0.33)$ & $0.23(0.75-0.52)$ & $0.18(0.05-0.40)$ \\
Small intestines & $0.21(0.13-0.34)$ & $0.26(0.17-0.59)$ & $0.27(0.17-0.40)$ \\
\hline
\end{tabular}

regional blood flow were for the full wall thickness at the small intestine and stomach, as for samples from the liver. Thus, the microsphere-determined estimate of flow expresses blood flow rates through the whole sample thickness. LSCI on the other hand assesses the microcirculation to a depth of only approximately $1 \mathrm{~mm}$ [30]. This discrepancy suggests a compensatory reduction in microcirculation in serosal and muscular layers to counteract a reduced mucosal circulation following induction of TEA, as proposed by the increased mucosal microcirculation with TEA by Michelet et al. [9].

Limitations of the present study include uncertainty regarding the precise position of the epidural catheters in pigs. Also, we did not demonstrate that the sympathetic nervous innervation to the splanchnic area was

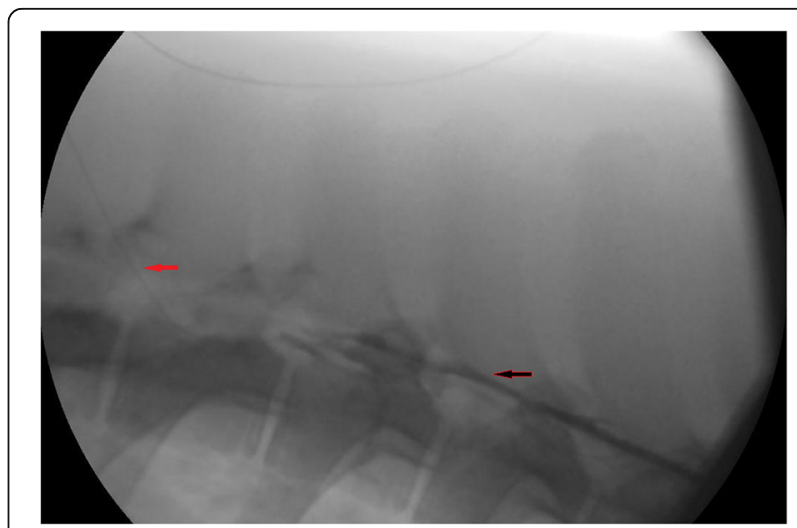

Fig. 5 An epidurogram after the placement of the epidural catheter. Red arrow: The epidural catheter. Black arrow: Position documented using a contrast agent during fluoroscopy 
blocked by TEA since, e.g., plasma catecholamines were not measured. However, the "loss of resistance" technique for establishing epidural anesthesia is a clinical standard procedure with low rate of failure [31] and has been used previously in porcine studies [7]. Therefore, based on the changes in the hemodynamic values following the induction of TEA (i.e., drop in systolic blood pressure and (non-significant) increase in heart rate), we believe that the catheters were positioned correctly. Nonetheless, we accept that, e.g., an epidurogram [32] could be used to identify the position of the catheters, which was used in subsequent investigations (Fig. 5). Another limitation to the study may be the dose of the local anesthetics used for epidural blockage, since the volume used was small and the effect on pigs is not well known. The chosen volume was based on studies using TEA in pigs $[7,32]$ and deduced from the experience with the doses and concentrations used at our department. Further, the current results seem to indicate a delayed block to the lower part of the spine, presented as a (non-significant) decrease in microcirculation at the small intestine $30 \mathrm{~min}$ following induction of TEA. Therefore, the volume used may be insufficient and/or the evaluation was made too early to reveal the longterm effects of epidural anesthesia on the microcirculation. Also, the study setup with the present study conducted after another investigation [12] may have affected the microcirculation and its regulation. This may, therefore, not fully resemble the effect of epidural analgesia during clinical situations, with the epidural block often activated prior to surgery. Furthermore, tissue oxygenation of the splanchnic organs was not assed and tissue oxygenation could have been maintained despite a reduced blood flow. However, reliable techniques for assessing tissue oxygenation requires contact to [33] or penetration of tissue surface [7], which could affect the microcirculation. In addition, the objective of the current study was to assess the LSCI technique for monitoring splanchnic microcirculation during TEA, in which we believe, was achieved.

\section{Conclusion}

The present study indicates that TEA may have an adverse effect on gastric microcirculation, as assessed by LSCI and microspheres in the pig. The results stress the need for randomized clinical trials to clarify the impact of TEA on gastric microcirculation. We suggest the non-touch technique offered by LSCI, to display changes in blood flow in real-time over a large area of tissue.

\section{Acknowledgments}

We wish to thank the personal at the Department of Experimental Medicine, The Panum Institute, University of Copenhagen for all the practical help.
Funding

The project was funded by the Danish Cancer Research Foundation.

\section{Availability of data and materials}

Data are not publicly available, since several reports regarding other aspects of this porcine model are unpublished. However, data are available from the corresponding authors on reasonable request.

\section{Authors' contributions}

RA contributed to the conception and design of the study, acquisition, analysis, and interpretation of data, and drafted the manuscript. NHS, KR, MPA, MBSS, and LBS contributed to the conception and design of the study and revision of the manuscript. RBS and LGP contributed to acquisition of data and revision of the manuscript. All authors gave final approval of the version to be published and agreed to be accoun for all aspects of the work.

\section{Competing interests}

The authors declare no conflict of interest.

\section{Consent for publication}

Not applicable.

\section{Ethics approval and consent to participate}

The study was approved by the Danish Animal Experiments Inspectorate: license no. 2012-15-2934-00186.

\section{Author details}

${ }^{1}$ Department of Surgical Gastroenterology C, Rigshospitalet, University of Copenhagen, Blegdamsvej 9, DK - 2100 Copenhagen Ø, Denmark. 2Department of Anesthesiology 2041, Rigshospitalet, University of Copenhagen, Blegdamsvej 9, DK - 2100 Copenhagen $\varnothing$, Denmark. ${ }^{3}$ Marine Biological Section, University of Copenhagen, Strandpromenaden 5, DK - 3000 Elsinore, Denmark.

Received: 26 April 2016 Accepted: 29 September 2016

Published online: 06 October 2016

\section{References}

1. Engquist A, Fog-Moller F, Christiansen C, Thode J, Vester-Andersen T, Madsen SN. Influence of epidural analgesia on the catecholamine and cyclic AMP responses to surgery. Acta Anaesthesiol Scand. 1980;24:17-21.

2. Popping DM, Elia N, Van Aken HK, Marret E, Schug SA, Kranke P, et al. Impact of epidural analgesia on mortality and morbidity after surgery: systematic review and meta-analysis of randomized controlled trials. Ann Surg. 2014;259:1056-67.

3. Richards ER, Kabir SI, McNaught CE, MacFie J. Effect of thoracic epidural anaesthesia on splanchnic blood flow. Br J Surg. 2013;100:316-21.

4. Pham TH, Perry KA, Enestvedt CK, Gareau D, Dolan JP, Sheppard BC, et al. Decreased conduit perfusion measured by spectroscopy is associated with anastomotic complications. Ann Thorac Surg. 2011;91:380-5.

5. Gould TH, Grace K, Thorne G, Thomas M. Effect of thoracic epidural anaesthesia on colonic blood flow. Br J Anaesth. 2002;89:446-51.

6. Lundberg J, Lundberg D, Norgren L, Ribbe E, Thorne J, Werner O. Intestinal hemodynamics during laparotomy: effects of thoracic epidural anesthesia and dopamine in humans. Anesth Analg. 1990;71:9-15.

7. Vagts DA, Iber T, Szabo B, Haberstroh J, Reising K, Puccini M, et al. Effects of epidural anaesthesia on intestinal oxygenation in pigs. Br J Anaesth. 2003; 90:212-20.

8. Meissner A, Weber TP, Van Aken H, Rolf N. Limited upper thoracic epidural block and splanchnic perfusion in dogs. Anesth Analg. 1999:89:1378-81.

9. Michelet P, Roch A, D'Journo XB, Blayac D, Barrau K, Papazian L, et al. Effect of thoracic epidural analgesia on gastric blood flow after oesophagectomy. Acta Anaesthesiol Scand. 2007;51:587-94.

10. Lange M, Hamahata A, Traber DL, Nakano Y, Traber LD, Enkhbaatar P. Multiple versus single injections of fluorescent microspheres for the determination of regional organ blood flow in septic sheep. Lab Anim. 2013:47:203-9.

11. Heymann MA, Payne BD, Hoffman Jl, Rudolph AM. Blood flow measurements with radionuclide-labeled particles. Prog Cardiovasc Dis. 1977;20:55-79. 
12. Ambrus R, Strandby RB, Svendsen LB, Achiam MP, Steffensen JF, Sondergaard Svendsen MB. Laser Speckle Contrast Imaging for Monitoring Changes in Microvascular Blood Flow. Eur Surg Res. 2016;56:87-96.

13. Burch RL, Russell WMS. The Principles of Human Experimental Technique. London: Methuen; 1959.

14. Reinhardt CP, Dalhberg S, Tries MA, Marcel R, Leppo JA. Stable labeled microspheres to measure perfusion: validation of a neutron activation assay technique. Am J Physiol Heart Circ Physiol. 2001;280:108-16.

15. Rousseau P, Mahe G, Haj-Yassin F, Durand S, Humeau A, Leftheriotis G, et al. Increasing the "region of interest" and "time of interest", both reduce the variability of blood flow measurements using laser speckle contrast imaging. Microvasc Res. 2011;82:88-91.

16. Meierhenrich R, Wagner F, Schutz W, Rockemann M, Steffen P, Senftleben U, et al. The effects of thoracic epidural anesthesia on hepatic blood flow in patients under general anesthesia. Anesth Analg. 2009;108:1331-7.

17. Tanaka N, Nagata N, Hamakawa T, Takasaki M. The effect of dopamine on hepatic blood flow in patients undergoing epidural anesthesia. Anesth Analg. 1997;85:286-90.

18. Trepenaitis D, Pundzius J, Macas A. The influence of thoracic epidural anesthesia on liver hemodynamics in patients under general anesthesia. Medicina (Kaunas). 2010;46:465-71.

19. Guyenet PG. The sympathetic control of blood pressure. Nat Rev Neurosci. 2006;:335-46

20. Hurley DP, Kremser PC, Gewertz BL. Regulation of intestinal blood flow with increased intraluminal pressure. J Surg Res. 1985;39:510-6.

21. Bohlen HG. Integration of intestinal structure, function, and microvascular regulation. Microcirculation. 1998:5:27-37.

22. Vollmar B, Menger MD. Intestinal ischemia/reperfusion: microcirculatory pathology and functional consequences. Langenbecks Arch Surg. 2011;396:13-29.

23. Ackland GM M. Physiology of the Gastrointestinal Tract Including Splanchnic Blood Flow and Tonometry. In: Kumar CM BM, editor. Gastrointestinal and colorectal anesthesia. New york: Informa Healthcare USA Inc; 2007. p. 1-12.

24. Lautt WW. Hepatic Circulation: Physiology and Pathophysiology. San Rafael (CA): Morgan \& Claypool Life Sciences; 2009. Chapter 12, Hepatic Circulation and Toxicology. https://www.ncbi.nlm.nih.gov/books/NBK53072/.

25. Lautt WW. Mechanism and role of intrinsic regulation of hepatic arterial blood flow: hepatic arterial buffer response. Am J Physiol. 1985;249:G549-56.

26. Lewis I. The surgical treatment of carcinoma of the oesophagus; with special reference to a new operation for growths of the middle third. $\mathrm{Br} J$ Surg. 1946;34:18-31.

27. Karliczek A, Benaron DA, Baas PC, Zeebregts Cl, van der Stoel A, Wiggers T, et al. Intraoperative assessment of microperfusion with visible light spectroscopy in esophageal and colorectal anastomoses. Eur Surg Res. 2008;41:303-11.

28. Alves A, Panis $Y$, Trancart D, Regimbeau JM, Pocard M, Valleur P. Factors associated with clinically significant anastomotic leakage after large bowel resection: multivariate analysis of 707 patients. World J Surg. 2002;26:499-502

29. Zehetner J, DeMeester SR, Alicuben ET, Oh DS, Lipham JC, Hagen JA, et al. Intraoperative Assessment of Perfusion of the Gastric Graft and Correlation With Anastomotic Leaks After Esophagectomy. Ann Surg. 2015;262:74-8.

30. Davis MA, Kazmi SM, Dunn AK. Imaging depth and multiple scattering in laser speckle contrast imaging. J Biomed Opt. 2014;19:086001.

31. Heinink TP, Baker BG, Yates VF, Addison DC, Williams JP. The effect of anaesthetist grade and frequency of insertion on epidural failure: a service evaluation in a United Kingdom teaching hospital. BMC Anesthesiol. 2015;15:5.

32. Bachmann KA, Trepte CJ, Tomkotter L, Hinsch A, Stork J, Bergmann W, et al. Effects of thoracic epidural anesthesia on sunvival and microcirculation in severe acute pancreatitis: a randomized experimental trial. Crit Care. 2013;17:R281.

33. Schwarte LA, Picker O, Hohne C, Fournell A, Scheeren TW. Effects of thoracic epidural anaesthesia on microvascular gastric mucosal oxygenation in physiological and compromised circulatory conditions in dogs. Br J Anaesth. 2004:93:552-9.

\section{Submit your next manuscript to BioMed Central and we will help you at every step:}

- We accept pre-submission inquiries

- Our selector tool helps you to find the most relevant journal

- We provide round the clock customer support

- Convenient online submission

- Thorough peer review

- Inclusion in PubMed and all major indexing services

- Maximum visibility for your research

Submit your manuscript at www.biomedcentral.com/submit

) Biomed Central 